\title{
Preoperative left atrial volume index is a predictor of successful sinus rhythm restoration and maintenance after the maze operation
}

Yong Hoon Kim, MD, ${ }^{a}$ Sang-Chol Lee, MD, ${ }^{\mathrm{b}}$ Ae Young Her, MD, ${ }^{a}$ Hak Jin Kim, MD, ${ }^{\text {b }}$ Jin Oh Choi, MD, ${ }^{\text {b }}$

Dae Hee Shin, MD, ${ }^{b}$ Sung Won Cho, MD, ${ }^{b}$ Wang Soo Lee, MD, ${ }^{\text {b }}$ Seung Woo Park, MD, ${ }^{\text {b }}$ and Pyo Won Park, MD

From the Department of Internal Medicine, ${ }^{a}$ College of Medicine, Kangwon National University, Chuncheon, Korea; and the Cardiac and Vascular Center, ${ }^{\mathrm{b}}$ Samsung Medical Center, Sungkyunkwan University School of Medicine, Seoul, Korea.

Received for publication May 18, 2006; revisions received Jan 26, 2007; accepted for publication Feb 5, 2007.

Address for reprints: Sang-Chol Lee, MD, Cardiac and Vascular Center, Samsung Medical Center, Sungkyunkwan University School of Medicine, 50 Irwon-dong, Gangnamgu, Seoul, 135-710, South Korea (E-mail: sclee@med.skku.ac.kr).

J Thorac Cardiovasc Surg 2007;134:448-53 $0022-5223 / \$ 32.00$

Copyright $\odot 2007$ by The American Association for Thoracic Surgery

doi:10.1016/j.jtcvs.2007.02.031
Objective: The purpose of this study was to identify the relationship of preoperative and postoperative left atrial volume indices and dimensions with successful restoration of sinus rhythm after the maze operation.

Methods: Forty-three patients who underwent the Cox-maze III procedure for permanent atrial fibrillation in conjunction with surgical intervention for various heart diseases were evaluated. Echocardiographic studies were performed preoperatively and 3 months postoperatively. Volumes and dimensions were corrected for body surface area and analyzed.

Results: Sinus rhythm was restored and maintained in $36(83.7 \%)$ of the 43 patients. The preoperative left atrial volume index of the group with successful restoration of sinus rhythm (group A) was significantly smaller than that of the group with unsuccessful restoration (group B: $76.7 \pm 16.4$ vs $108.9 \pm 43.9 \mathrm{~mL} / \mathrm{m}^{2}, P=.047$ ). In group A the volume index $\left(76.7 \pm 16.4 \mathrm{vs} 52.3 \pm 15.0 \mathrm{~mL} / \mathrm{m}^{2}, P<.001\right)$ and dimension index $\left(35.8 \pm 6.2\right.$ vs $\left.30.8 \pm 4.7 \mathrm{~mL} / \mathrm{m}^{2}, P<.001\right)$ decreased significantly 3 months after the operation. No such significant changes were found in group B. The duration of arrhythmia for group A was significantly shorter than that for group B $(3.4 \pm 2.8$ vs $13.7 \pm 8$ years, $P=.001)$.

Conclusions: The preoperative left atrial volume index, as opposed to the conventional left atrial dimension, and the duration of arrhythmia are important predictors of successful sinus rhythm restoration after the maze operation. A significant reduction of the volume index can be achieved in patients whose rhythm is successfully restored and maintained after the procedure.

A trial fibrillation (AF) is the most common sustained arrhythmia, with an overall prevalence of $0.4 \% .{ }^{1} \mathrm{AF}$ is present in $2.3 \%$ of persons older than 40 years and in $5.9 \%$ of those older than 65 years. $^{2}$ It is associated with a 2 -fold increase in cardiac mortality and, in the absence of adequate anticoagulation therapy, with a 5 -fold increase in the risk for stroke. ${ }^{3}$ The maze procedure, initially reported by Cox and colleagues, ${ }^{4}$ has been used to improve hemodynamics and decrease the risk of systemic thromboembolism by restoring atrioventricular synchrony in patients with $\mathrm{AF}^{5}$

Echocardiographically determined left atrial size is known to be closely associated with the development of $\mathrm{AF}^{6}{ }^{6}$ and left atrial diameter (LAD) has been reported to be an independent predictor of sinus rhythm restoration after the maze procedure. $^{7}$ There also have been reports noting that the predictive value of left atrial volume (LAV) on the risk for AF in elderly patients is incremental to that of the clinical risk profiles and the conventional M-mode left atrial dimension. The purpose of this study was to identify the relationship of preoperative and postop- 


\section{Abbreviations and Acronyms \\ $\mathrm{AF}=$ atrial fibrillation \\ $\mathrm{LAD}=$ left atrial diameter \\ $\mathrm{LAV}=$ left atrial volume}

erative LAV and LAD with the successful restoration and maintenance of sinus rhythm after the maze procedure.

\section{Materials and Methods \\ Subjects}

A retrospective evaluation was performed on 43 consecutive patients with permanent AF who underwent the Cox-maze III procedure combined with other types of cardiac surgery during a period of 27 months (between October 2002 and December 2004) at Samsung Medical Center, Seoul, Korea. Our study followed the guidelines of the ethical review board of Samsung Medical Center. Clinical characteristics, including combined heart disease, presence of rheumatic heart disease, New York Heart Association functional class, and duration of AF, were noted and evaluated. The patients were separated into 2 groups according to history and electrocardiographic findings. Group A consisted of 36 patients (18 men and 18 women; mean age, $52.9 \pm 12.7$ years; age range, 27-72 years) with successful restoration of sinus rhythm after surgical intervention, and group B consisted of 7 patients ( 3 men and 4 women; mean age, $60.4 \pm 11.2$ years; age range, 46-71 years) whose restoration of sinus rhythm was unsuccessful.

\section{Combined Cardiac Diseases and Other Major Cardiac Surgery}

All patients had combined organic heart diseases (21 with triplevalve diseases, 18 with double-valve diseases, 3 with mitral valve disease only, and 1 with tricuspid regurgitation). Two patients concomitantly had congenital heart diseases (atrial septal defect and ventricular septal defect, Table 1). The operations performed in conjunction with the maze III operation were as follows: mitral valvuloplasty, 10 cases; mitral valve replacement, 21 cases; open mitral commissurotomy, 4 cases; aortic valve valvuloplasty, 5 cases; aortic valve replacement, 8 cases; tricuspid valve repair, 24 cases; atrial septal closure, 1 case; and ventricular septal defect closure, 1 case.

\section{Method of the Maze Procedure}

The maze procedure was performed with long cryoprobes. Custommade straight $(6 \mathrm{~cm})$ and T-shaped $(5 \mathrm{~cm})$ long cryoprobes (Frigitronics, Cooper Surgical) were used and applied to separate sites for 2 minutes and 30 seconds each at a temperature of $-60^{\circ} \mathrm{C}$. The left atrial box and connecting lesion into the posterior mitral annulus were made. The left atrial appendage was closed internally without excision, and the LAV reduction procedure was not used in any case. The right atrial isthmus lesion was created and extended to the left atrial surgical incision. We occasionally added a lesion from right atrial appendage to the tricuspid valve annulus in case of a dilated right atrium.
TABLE 1. Preoperative patient characteristics: Comparison between successful and unsuccessful sinus rhythm restoration

\begin{tabular}{|c|c|c|c|}
\hline & $\begin{array}{l}\text { Group A } \\
(\mathrm{n}=36)\end{array}$ & $\begin{array}{c}\text { Group B } \\
(n=7)\end{array}$ & $P$ value \\
\hline Age (y) & $52.9 \pm 12.7$ & $60.4 \pm 11.2$ & NS \\
\hline $\operatorname{Sex}(M / F)$ & $18 / 18$ & $3 / 4$ & NS \\
\hline NYHA (I/II/III/IV) & $1 / 19 / 16 / 0$ & $1 / 4 / 2 / 0$ & NS \\
\hline \multicolumn{4}{|l|}{ Associated conditions } \\
\hline MVD & $2(5.6 \%)$ & $1(14.3 \%)$ & \\
\hline $\mathrm{TR}$ & 0 & $1(14.3 \%)$ & \\
\hline MVD + TR & $16(44.4 \%)$ & $2(28.6 \%)$ & \\
\hline $\mathrm{MVD}+\mathrm{AVD}+\mathrm{TR}$ & $18(50.0 \%)$ & $3(42.6 \%)$ & \\
\hline Rheumatic heart disease & $25(69.4 \%)$ & $5(71.4 \%)$ & \\
\hline
\end{tabular}

Group $A$, Successful restoration of sinus rhythm after the maze III operation; group $B$, unsuccessful restoration of sinus rhythm after the maze III operation; NS, not significant; NYHA, New York Heart Association functional class; $M V D$, mitral valve disease; $T R$, tricuspid regurgitation; AVD, aortic valve disease.

\section{Echocardiography}

Transthoracic echocardiographic images were obtained by using commercially available echocardiography machines (Sequoia system, Acuson-Siemens, and Vivid 7 system, GE) equipped with 2.5-MHz transducers. Left ventricular ejection fraction was calculated by using the modified Simpson method. Left atrial dimensions were measured on an M-mode tracing taken from a parasternal long-axis view. The dimensions were corrected to body surface area (LAD index). LAVs were assessed by using the ellipsoid (length-diameter) method (see equations 1 and 2 below). ${ }^{8-10}$ Anteroposterior (D1) and mediolateral (D2) dimensions were measured from the parasternal long- and short-axis views. The superoinferior (D3) dimension was measured from the apical 4-chamber view (Figure 1). Both the absolute volume and the volume indexed to body surface area (LAV index) were obtained.

$$
\begin{gathered}
L A V \text { index }=(4 / 3 \pi \times D 1 / 2 \times D 2 / 2 \times D 3 / 2) / B S A \\
L A D \text { index }=L A D / B S A
\end{gathered}
$$

where BSA is defined as body surface area.

The presence of left atrial mechanical function was determined by the presence of the A wave of mitral inflow on Doppler echocardiography. ${ }^{11}$ When the presence of an A wave was ambiguous, the atrial reversal flow of the pulmonary venous flow was used as a surrogate.

\section{Follow-up Studies}

Follow-up echocardiographic examinations for evaluation of LADs and LAVs and the presence of atrial mechanical function were performed at 3 months after the operation in the manner described above.

\section{Statistics}

For all statistical calculations, the SPSS 10.0 (SPSS, Inc) program was used. Categoric variables were compared by using the $\chi^{2}$ or Fisher exact tests. The Mann-Whitney $U$ test and Wilcoxon rank 
A

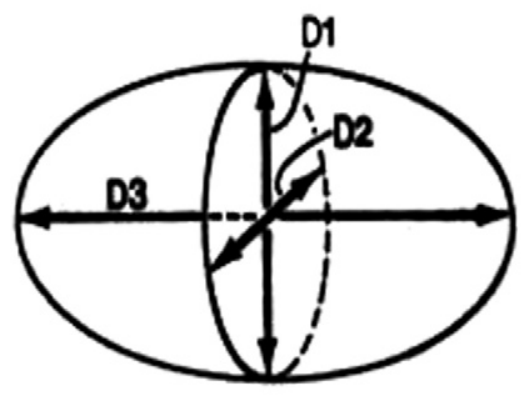

C

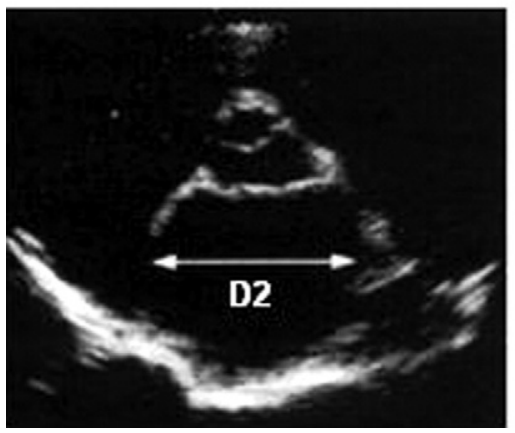

B

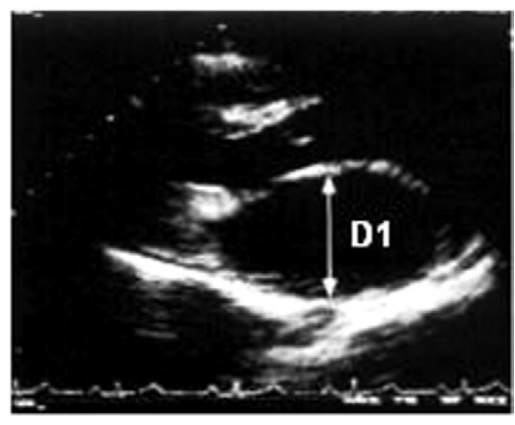

D

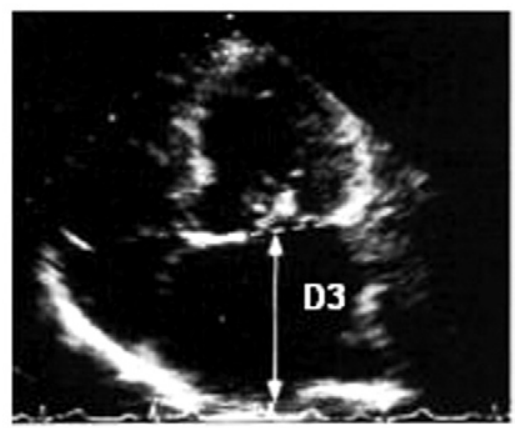

Figure 1. Left atrial volume assessed by means of the length-diameter ellipsoid method. Anteroposterior dimension (D1; $A$ and $B$ ), mediolateral dimension (D2; $A$ and $C)$, and superoinferior dimension (D3; $A$ and $D$ ). sum tests were used for the comparison of nonparametric samples. Correlation between the duration of AF and LAV was analyzed by using the Spearman correlation method. Values are expressed as means \pm standard deviations.

\section{Results}

\section{Patient Characteristics and Left Ventricular}

Ejection Fraction

Patient characteristics are listed in Table 1. There was no significant difference between the 2 groups in terms of age, sex, New York Heart Association functional class, or presence of rheumatic heart disease. The mean duration of $\mathrm{AF}$ for group A was significantly shorter than that for group B $(3.4 \pm 2.8$ vs $13.7 \pm 8$ years, $P=.001)$. There was no difference in preoperative left ventricular ejection fraction between the groups (Table 2). None of the subjects in either group had significant mitral regurgitation at the 3-month follow-up.

\section{Preoperative and Postoperative LAVs}

The preoperative LAV index of group A was significantly smaller than that of group B $(76.7 \pm 16.4$ vs $108.9 \pm$ $43.9 \mathrm{~mL} / \mathrm{m}^{2}$, respectively; $P=.04$ ). No such finding could be found when the volume data were not indexed $(89.9 \pm 23.3$ vs $137.1 \pm 50.4 \mathrm{~mL}$, respectively; $P=.11)$. At follow-up, there was a significant decrease in the LAV index for group A $(P<.001)$, with no such decrease observed for group B $(P=.084)$, and the difference between the groups was more prominent $(52.3 \pm 15.0$ vs $98.1 \pm 35.5 \mathrm{~mL} / \mathrm{m}^{2}$, respectively; $P<.001$; Table 2 ).

\section{Preoperative and Postoperative LADs}

The preoperative LADs and LAD indices for groups $\mathrm{A}$ and B were $58.1 \pm 8.1$ versus $63.4 \pm 7.6 \mathrm{~mm}$ and $35.8 \pm 6.2 \mathrm{vs}$ $37.7 \pm 7.7 \mathrm{~mm} / \mathrm{m}^{2}$, respectively, with no significant difference between the groups in either value. There was a significant difference in the indices 3 months after the operation $\left(30.8 \pm 4.7\right.$ and $35.3 \pm 8.5 \mathrm{~mm} / \mathrm{m}^{2}$, respectively; $P=.03$; Table 2), the decrease in the LAD index for group A was statistically significant $(P<.001)$, and there was no significant change found for group B (Figure 2).

\section{Association Between the Duration of Arrhythmia and Atrial Size}

Because atrial size can be suspected to increase with prolongation of arrhythmia, we evaluated the possible association between LAV/LAD index and the duration of AF. However, no significant correlation could be found between the variables.

\section{Effect of the Maze Procedure on Left Atrial Mechanical Function in Group A}

For group A, left atrial mechanical function was demonstrated in $58.3 \%$ at follow-up. However, no significant as- 
TABLE 2. Comparison of echocardiographic parameters and the duration of atrial fibrillation between groups with successful and unsuccessful sinus rhythm restoration after the maze procedure

\begin{tabular}{lccc}
\hline Parameters & Group A & Group B & $P$ value \\
\hline EF (\%) & & & \\
Before operation & $58.5 \pm 9.4$ & $61.1 \pm 10.2$ & NS \\
$\quad$ After operation & $60.4 \pm 10.2$ & $61.2 \pm 4.4$ & NS \\
LAD (mm) & & & \\
$\quad$ Before operation & $58.1 \pm 8.1$ & $63.4 \pm 7.6$ & NS \\
After operation & $49.9 \pm 6.9$ & $59.7 \pm 10.1$ & NS \\
LAD index (mm/m ${ }^{2}$ ) & & & \\
Before operation & $35.8 \pm 6.2$ & $37.7 \pm 7.7$ & NS \\
$\quad$ After operation & $30.8 \pm 4.7$ & $35.3 \pm 8.5$ & .03 \\
LAV (mL) & & & \\
$\quad$ Before operation & $89.9 \pm 23.3$ & $137.1 \pm 50.4$ & NS \\
$\quad$ After operation & $78.5 \pm 17.4$ & $127.3 \pm 47.5$ & .003 \\
LAV index (mL/m ${ }^{2}$ ) & & & \\
Before operation & $76.7 \pm 16.4$ & $108.9 \pm 43.9$ & .04 \\
After operation & $52.3 \pm 15.0$ & $98.1 \pm 35.5$ & $<.001$ \\
Duration of AF (y) & $3.4 \pm 2.8$ & $13.7 \pm 8$ & .001 \\
\hline
\end{tabular}

$E F$, Ejection fraction; $N S$, not significant; $L A D$, left atrial diameter; $L A V$, left atrial volume; $A F$, atrial fibrillation.

sociation was found between the restoration of mechanical function and the LAD index or LAV index (Table 3).

\section{Discussion}

AF is a highly prevalent age-related condition associated with pronounced morbidity, mortality, and socioeconomic burden, ${ }^{3}$ which can cause or exacerbate heart failure, can substantially affect quality of life, and accounts for more hospitalization days than any other arrhythmia. ${ }^{12}$ Therefore proper management of this arrhythmia has been an important aspect of current practice in clinical cardiology. ${ }^{13-15}$

Several reports have been published regarding the rate of sinus rhythm restoration after the maze procedure. Cox and colleagues ${ }^{5}$ reported a success rate of $98 \%$ in 65 patients; when the operation was performed in patients with structural heart disease, ${ }^{16}$ conversion was achieved in $82 \%$ (83/ 101 patients), and when the procedure was combined with another cardiac operation, ${ }^{7}$ the restoration rate was reported to be approximately $79 \%$. In our study $83.7 \%$ of patients were successfully converted to and maintained sinus rhythm after surgical intervention, showing a figure consistent with the data from prior reports.

As the size of the left atrium has been shown to be a significant factor in the development and maintenance of $\mathrm{AF},{ }^{7,17}$ it might also be an important factor for predicting successful restoration of sinus rhythm after the maze procedure. Kamata and associates ${ }^{7}$ demonstrated that the left atrial dimension was an independent predictor of sinus rhythm restoration after the procedure, and Yashima and coworkers ${ }^{18}$ reported that in patients with nonrheumatic mitral valve disease who underwent this operation, a significant negative correlation was observed between the preoperative left atrial dimension and the left atrial contractile function at the late postoperative phase. However, the left atrial dimension is a unidimensional value that sometimes underestimates or overestimates the true size of the left atrium. For this reason, estimation of the LAV might be needed to accurately measure the atrial size and predict the possibility of sinus rhythm restoration after the maze procedure. Our results clearly show that the preoperative LAV, especially when indexed to body surface, is a good predictor of rhythm restoration after the procedure, whereas the preoperative LAD indices could not predict the follow-up results. A preoperative echocardiographic evaluation in subjects with AF should therefore definitely include measurement of the LAV index.

The duration of AF has also been shown to be an issue relevant to successful conversion of the arrhythmia, either medical or surgical. Kosakai and others ${ }^{16,19}$ have noted that patients who remained in AF after the operation had a longer duration of AF before surgical intervention. Our study results are in concordance with these previous reports, with a difference of 10 years in duration of AF between the successful and unsuccessful groups.

As with the follow-up data, Chen and associates ${ }^{20}$ demonstrated that at 3 months' follow-up after the maze procedure, a reduction in atrial size appeared to predict the success of sinus conversion when the procedure was performed in conjunction with valvular heart surgery. Our results also confirm this finding, with a significant reduction in atrial volume in the successfully maintained group at follow-up.

The recovery rate of left atrial function, which was around $60 \%$ in our study, was similar to those previously reported. ${ }^{5,21}$ Disappointingly, neither LAV nor LAD index showed significant associations with recovery of atrial function. This might have been a result of the relatively small study population, and further studies are warranted to elucidate this aspect of management of AF.

\section{Study Limitations}

There are some limitations of this study that must be recognized. First, our results might have been partially skewed because of the relatively small total study population and the number of cases of unsuccessful sinus rhythm restoration; however, we think that the clear difference between the successful and unsuccessful groups makes our results sufficiently valid. Second, because of the short duration of follow-up, we cannot conclude that our results can be extended to a longer period of follow-up. Further prospective studies should be carried out for a longer term to verify our results. Third, it might have been very useful 
Group A

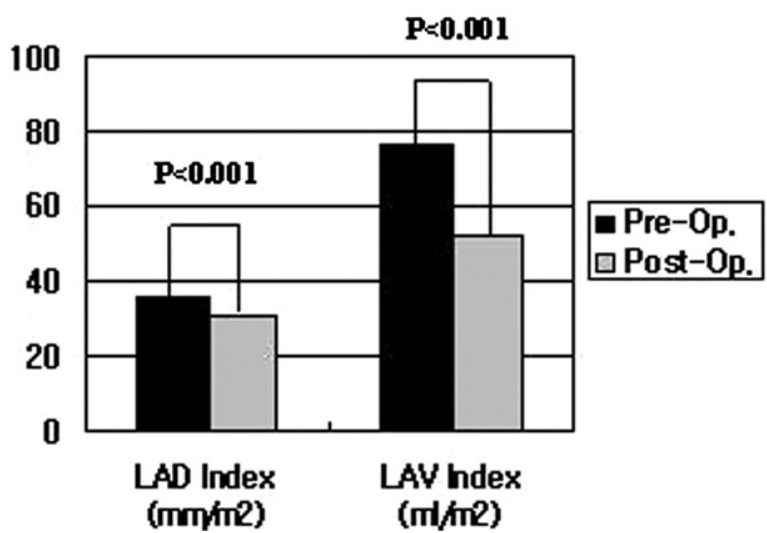

\section{Group B}

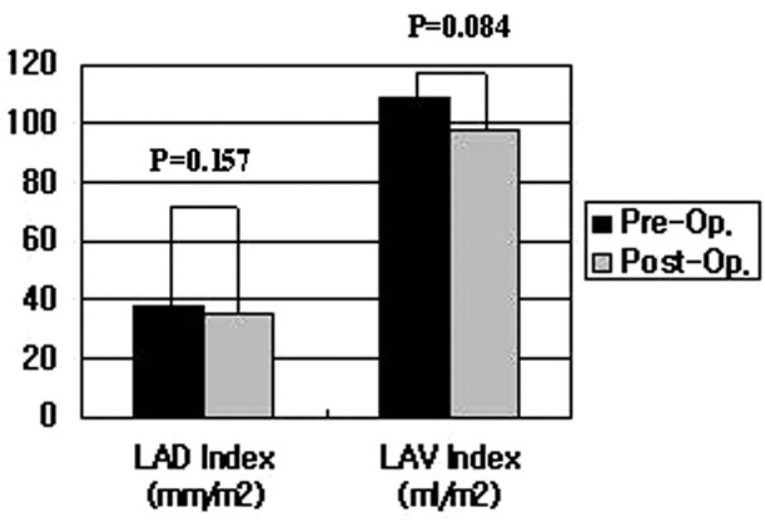

Figure 2. Comparison of left atrial dimension (LAD) index and left atrial volume (LAV) index between before and after the maze operation. Group $A$, Successful restoration of sinus rhythm after the maze procedure; group $B$, unsuccessful restoration of sinus rhythm after the maze procedure.

TABLE 3. Comparison between left atrial mechanical function and left atrial diameter and left atrial volume indices in patients whose sinus rhythm was successfully restored after the maze procedure

\begin{tabular}{llll}
\hline Parameters & $\begin{array}{c}\text { LA activity } \\
(+; \mathbf{n}=\mathbf{2 1})\end{array}$ & $\begin{array}{c}\text { LA activity } \\
(-; \mathbf{n}=\mathbf{1 5})\end{array}$ & $\boldsymbol{P}$ value \\
\hline LAD index $\left(\mathrm{mm} / \mathrm{m}^{2}\right)$ & $30.1 \pm 2.8$ & $31.1 \pm 3.2$ & NS \\
LAV index $\left(\mathrm{mL} / \mathrm{m}^{2}\right)$ & $51.2 \pm 11.1$ & $53.3 \pm 16.2$ & NS
\end{tabular}

$L A$, Left atrium; $L A D$, left atrial dimension; $N S$, not significant; $L A V$, left atrial volume.

if we could have performed a linear regression analysis and obtained a receiver operating characteristic curve to produce a cutoff value for recommending the maze procedure. However, because the study population (especially the number of failed cases) was too small and the data did not follow a normal distribution pattern, such an analysis was not considered suitable with our dataset. Further studies might focus on this point and produce such a value.

\section{Conclusions}

The preoperative LAV index measured by means of echocardiography and the duration of AF are significant predictors of successful sinus rhythm restoration after the maze III procedure. Significant reduction of the LAV index after the maze III operation can be found in patients whose rhythm is successfully restored and maintained.

We thank Dr Dong-Ryeol Ryu for his exceptional effort in obtaining the clinical data for completion of this study.

\section{References}

1. Ostrander LD Jr, Brandt RL, Kjelsberg MO, Epstein FH. Electrocardiographic findings among the adult population of a total natural community, Tecumseh, Michigan. Circulation. 1965;31:888-98.

2. Feinberg WM, Blackshear JL, Laupacis A, Kronmal R, Hart RG. Prevalence, age distribution, and gender of patients with atrial fibrillation. Analysis and implications. Arch Intern Med. 1995;155:469-73.

3. Wolf PA, Abbott RD, Kannel WB. Atrial fibrillation: a major contributor to stroke in the elderly. The Framingham Study. Arch Intern Med. 1987;147:1561-4.

4. Cox JL, Schuessler RB, D’Agostino HJ Jr, Stone CM, Chang BC, Cain ME, et al. The surgical treatment of atrial fibrillation. III. Development of a definitive surgical procedure. J Thorac Cardiovasc Surg. 1991; 101:569-83.

5. Cox JL, Boineau JP, Schuessler RB, Kater KM, Lappas DG. Five-year experience with the maze procedure for atrial fibrillation. Ann Thorac Surg. 1993;56:814-24.

6. Henry WL, Morganroth J, Pearlman AS, Clark CE, Redwood DR, Itscoitz SB, et al. Relation between echocardiographically determined left atrial size and atrial fibrillation. Circulation. 1976;53:273-9.

7. Kamata J, Kawazoe K, Izumoto H, Kitahara H, Shiina Y, Sato Y, et al. Predictors of sinus rhythm restoration after Cox maze procedure concomitant with other cardiac operations. Ann Thorac Surg. 1997;64:394-8.

8. Arcilla RA, Thilenius OG, Chiemmongkolip P, Ranniger K. Left atrial volume calculation by angiocardiography in children. Chest. 1973;63: 189-97.

9. Ren JF, Kotler MN, DePace NL, Mintz GS, Kimbiris D, Kalman P, et al. Two-dimensional echocardiographic determination of left atrial emptying volume: a noninvasive index in quantifying the degree of nonrheumatic mitral regurgitation. J Am Coll Cardiol. 1983;2:729-36.

10. Sanfilippo AJ, Abascal VM, Sheehan M, Oertel LB, Harrigan P, Hughes RA, et al. Atrial enlargement as a consequence of atrial fibrillation. A prospective echocardiographic study. Circulation. 1990;82:792-7.

11. Manning WJ, Leeman DE, Gotch PJ, Come PC. Pulsed Doppler evaluation of atrial mechanical function after electrical cardioversion of atrial fibrillation. J Am Coll Cardiol. 1989;13:617-23.

12. 2001 heart and stroke statistical update. Dallas, Tex: American Heart Association; 2000.

13. Cannom DS. Atrial fibrillation: nonpharmacologic approaches. Am J Cardiol. 2000;85:25D-35D.

14. Falk RH. Atrial fibrillation. N Engl J Med. 2001;344:1067-78.

15. Heinz G. Atrial fibrillation in the intensive care unit. Intensive Care Med. 2006;32:345-8. 
16. Kosakai Y, Kawaguchi AT, Isobe F, Sasako Y, Nakano K, Eishi K, et al. Modified maze procedure for patients with atrial fibrillation undergoing simultaneous open heart surgery. Circulation. 1995; 92(suppl II):II359-64.

17. Chen MC, Chang JP, Chang HW. Preoperative atrial size predicts the success of radiofrequency maze procedure for permanent atrial fibrillation in patients undergoing concomitant valvular surgery. Chest. 2004;125:2129-34.

18. Yashima N, Nasu M, Kawazoe K, Hiramori K. Serial evaluation of atrial function by Doppler echocardiography after the maze procedure for chronic atrial fibrillation. Eur Heart J. 1997;18:496-502.
19. Kosakai Y, Kawaguchi AT, Isobe F, Sasako Y, Nakano K, Eishi K, et al. Cox maze procedure for chronic atrial fibrillation associated with mitral valve disease. J Thorac Cardiovasc Surg. 1994; 108:1049-55.

20. Chen MC, Chang JP, Guo GB, Chang HW. Atrial size reduction as a predictor of the success of radiofrequency maze procedure for chronic atrial fibrillation in patients undergoing concomitant valvular surgery. $J$ Cardiovasc Electrophysiol. 2001;12:867-74.

21. Shyu K, Cheng J, Chen J, Lin J, Lin F, Tseng Y, et al. Recovery of atrial function after atrial compartment operation for chronic atrial fibrillation in mitral valve disease. J Am Coll Cardiol. 1994;24: $329-8$. 